\title{
EL ALOJAMIENTO DE LAS FAMILIAS ARGELINAS Y LAS RELACIONES INTERGENERACIONALES
}

\author{
Emmanuelle Santelli \\ Socióloga, lnstitut des Sciences de l' Homme (Lyon)
}

\begin{abstract}
Los espacios residenciales de las poblaciones inmigrantes no pueden comprenderse únicamente en referencia a los temas de la segregación. A partir de tres aspectos como son la localización residencial, el ascenso a la propiedad de la vivienda y los intercambios -financieros y moralesentre generaciones, la autora muestra cómo el estudio de las prácticas de movilidad residencial de las familias inmigrantes de origen argelino instaladas en la región lionesa nos permite aprehender sus trayectorias sociales en el seno de la sociedad francesa. No puede ignorarse el carácter plural de tales experiencias y, por tanto, la necesidad de escarpar a las representaciones fuertemente homogéneas de las que, comúnmente, se derivan un conjunto de imágenes negativas. Se subraya también cómo los itinerarios residenciales inciden sobre las prácticas y estructuras familiares y en las relaciones intergeneracionales.
\end{abstract}

$\mathrm{E}$ 1 tema del alojamiento y de los itinerarios residenciales es uno de los aspectos de un trabajo de investigación más amplio realizado sobre las familias de inmigrantes argelinas en Francial. El estudio de los espacios habitados y los desplazamientos residenciales introduce a otras formas de itinerarios sociales a la vez que nos enseña sus interacciones: ayuda a comprender la formación de las diversas trayectorias sociales. El carácter polifacético de este tema señala su pertinencia para analizar procesos sociales: no tanto el análisis de situaciones residenciales como la de los procesos que ponen de manifiesto todas las dimensiones del alojamiento y la ciudad, o dicho de otro modo, de los modos de habitar. El análisis del itinerario residencial de los padres, los emigrados, y de sus hijos, ilustra su manera de habitar el espacio residencial (interior y exterior) $y$, más ampliamente, su modo de habitar en la sociedad francesa.

En realidad, investigar el itinerario residencial y sus prácticas subyacentes (tipo de alojamiento, ordenación, relación con el vecindario, etc.), constituye una de las maneras de aprehender los modos de integración en la sociedad, independientemente de la generación estudiada. El Sr. Gribaudi denomina 
«ciclo de integración urbana» ${ }^{2}$ (pp. 76/77): «[El fenómeno migratorio] y el itinerario residencial no son los únicos elementos que nos permiten captar la existencia de un ciclo de implantación en la ciudad y de integración en la vida social de Turín. Existe también un itinerario geográfico (...) que se debe tener en cuenta, la antiguiedad de la integración de los actores sociales (...) con el fin de aclarar las determinaciones individuales y familiares que les han inducido a desplazarse». Es importante entonces intentar responder a ciertas preguntas, con el fin de aprehender el contexto en el que se han elaborado los itinerarios de la segunda generación: ¿Qué tipo de alojamiento han ocupado desde su llegada? ¿Qué tipo de relación han mantenido con la vecindad? ¿Cuál ha sido la incidencia de estas relaciones sobre la organización familiar? En les, es la historia de la familia antes de su inmigración y desde su establecimiento en Francia, especialmente a través de los espacios habitados, lo que permite introducirnos en el universo social desde el cual se han construido los referentes, las relaciones de sociabilidad, las aspiraciones, etc. de los hijos. El hábitat representa mucho más que un lugar: es el resultado de una compensación y/o de estrategias (la movilidad residencial como sustituto de la movilidad profesional; la incorporación a un alojamiento que permite crear una empresa gracias a este capital disponible). El hábitat permite también una mezcla social y/o cultural más o menos fuerte entre las personas (co-presencia de personas que tienen orígenes $y / o$ pertenencias sociales $o$ culturales diferentes). El espacio habitado

pone de manifiesto también las relaciones de solidaridad entre vecinos, entre miembros de la familia... Finalmente, quizás sea la ocasión de una movilización (para su adquisición, restauración...), la estrategia de una búsqueda de proximidad-distancia frente al antiguo lugar de residencia, de los otros miembros de la familia, de la comunidad de origen, etc.

A pesar de una representación muy homogénea de la población inmigrada y de su trayectoria en Francia, cuyo arquetipo del espacio residencial es el extrarradio, el carácter plural de las trayectorias residenciales de estas familias invita a relativizar esta imagen negativa que tiene como corolario creer que todos los inmigrantes están recluidos en los espacios más degradados.

Por lo tanto, a partir de los tres siguientes temas, la localización residencial, el acceso a la propiedad y el intercambio de ayudas que vinculan las dos generaciones, se trata de mostrar cómo las prácticas residenciales permiten aprehender los itinerarios sociales en la sociedad francesa, prestando especial atención precisamente a su diversidad.

No es la intención negar que existen grandes dificultades para las familias inmigradas ostensibles, por ejemplo, en la imposibilidad de mudarse (política tácita de cuotas de los municipios y de los organismos proveedores de fondos públicos), en las prácticas discriminatorias y/o en la asignación de alojamientos degradados y extremadamente viejos, etc. En cambio, el objetivo de mi trabajo se centró no tanto en estos obstáculos como en observar a posteriori el itinerario residencial efectuado 
por sus familiares como etapa de la historia individual y familiar. De ahí que el análisis del hábitat y de las movilidades residenciales sea un eje central para comprender la evolución de la sociedad francesa.

\section{La localización residencial}

Muchos trabajos han descrito la distribución de las distintas poblaciones establecidas (según el origen, la categoría socio-profesional, etc.) en los territorios urbanos y los efectos de segregación que la acompañan (según el periodo de llegada en la ciudad, las distribuciones por sectores de actividad, etc. $)^{3}$. La localización de las familias argelinas en la región de Lyon obedece a estos principios: estas familias residen esencialmente en los municipios del sureste, sector donde se han instalado las empresas industriales ${ }^{4}$ (o sea Feysin, Vénissieux y el Distrito VIII especialmente). Algunos barrios del centro de la ciudad han recibido también diferentes oleadas de inmigrantes (sobre todo los barrios de la Guillotière, de la Place du Pont $)^{5}$.

Aunque la localización de las familias argelinas parece ser evidente, es importante, sin embargo, distinguir los periodos (por ejemplo, ¿cuáles son los diferentes espacios habitados a lo largo del itinerario residencial de una familia?), así como el tipo de alojamiento ocupado según los espacios. Si las viviendas $\mathrm{HLM}^{6}$ se encuentran en su gran mayoría en el primer anillo de la aglomeración, no quita que los primeros alojamientos ocupados no son necesariamente de protección oficial. Además, las viviendas a las que las familias han podido acceder posteriormente están ubica- das, bien en el segundo anillo o en barrios donde no habían tenido acceso antes. Finalmente, a pequeña escala, cuáles son las implicaciones de las diferentes localizaciones para la familia ( $;$ se han encontrado con familias del mismo origen o en un entorno más heterogéneo social y/o culturalmente? ¿Cuáles son entonces los efectos sobre la organización familiar?).

Por lo tanto, se trata de cruzar datos en el tiempo, del periodo analizado, del tipo de alojamiento, del espacio socio-residencial, con el objetivo de no limitar nuestra percepción de la situación observada al día $J$ de la encuesta o, peor, sólo a las representaciones del «alojamiento inmigrado». Se trata de evitar reducir la situación de una mayoría ${ }^{7}$ al conjunto de esta población, por una parte $y$, por otra, distinguir los efectos a lo largo del tiempo. De hecho, se confunde frecuentemente «viviendas sociales y familias de inmigrantes» mientras que su acceso a este tipo de vivienda data sólo de los años 1970/80 (gran parte de las familias habían llegado muchos años antes). Por lo tanto, hay muchas personas que han ocupado otros espacios residenciales antes de tener acceso a una vivienda social o que sólo pasaron una temporada en ella para luego adquirir otra vivienda. Finalmente, vivir en un barrio de viviendas sociales no significa necesariamente vivir en una «vivienda asignada»

No quita que lo que caracteriza a las formas del hábitat desde la llegada de esta población es su carácter rudimentario, hasta insalubre (saloncillo, hotel amueblado, apartamento en el viejo inmueble destartalado del centro de la ciudad, muchas veces derruido a causa de las 
políticas de gentrificación, chabolas, viejas casas sin comodidades, cuando no se trata de un vagón de tren o un autobús desafectado puesto a disposición de la familia por el empleador del padre). Aunque estas viviendas hayan permanecido modestas y con escasas comodidades (deficiente o inexistente calefacción, ausencia de servicios sanitarios, agua caliente, a veces agua corriente, humedades, etc.) siguen teniendo una connotación positiva para los entrevistados que las utilizan como punto de referencia para evaluar sus siguientes viviendas. A partir de ellas, las familias buscarán vivir en una casa, cultivar un jardín, tener espacio. Otros van a privilegiar la proximidad con las familias francesas para no vivir en el extrarradio, en barrios despreciados por el predominio de poblaciones de origen extranjero, para no ser estigmatizados. Fue solamente en una segunda etapa cuando una parte de estas familias obtuvo una vivienda social en un barrio periférico, lo que significaba con relación a las condiciones anteriores, una clara mejora de su condición de alojamiento.

Sin embargo, si el itinerario residencial «clásico» les ha conducido desde las viviendas más insalubres a las viviendas sociales, algunas familias han tenido acceso «directamente» a otros tipos de viviendas como, por ejemplo, una vivienda en el centro de la ciudad, en la ciudad obrera, en un pueblo rural, una vivienda alquilada por un organismo social fuera del extrarradio, etc. De modo que, a pesar de la aparente similitud del itinerario migratorio y residencial ${ }^{9}$, constatamos que no todos han conocido los mismos itinerarios residenciales, ni las mismas experiencias dentro de los barrios. Por ejemplo, dos familias que viven en el barrio Vaulx-en-Velin pueden tener una experiencia del espacio urbano muy diferente y prácticas socio-familiares distintas. En un caso, una familia va a fomentar el repliegue sobre la comunidad de origen del barrio y, en el otro, va a permitir una apertura a la sociedad mediante actividades para-escolares ofrecidas a los niños, amistades aprobadas con los amigos de origen francés, etc.

Las localizaciones residenciales predisponen, hasta cierto punto, a la heterogeneidad social y cultural de los habitantes. Ahora bien, este enfrentamiento entre una mayor o menor heterogeneidad del vecindario, mediante universos de referencia, modos de percepción, prácticas que se establecen dentro de los espacios residenciales, tiene repercusiones sobre los habitantes y especialmente sobre los niños que están expuestos a procesos de socialización diferentes, incluso contradictorios. Sin llegar a saber qué tipo de espacio residencial es el más favorable, cabe constatar que el lugar donde las personas han vivido, desde el cual han construido sus referencias... nos ayuda a comprender las trayectorias sociales, la formación de un horizonte de lo posible, tanto a escala individual como familiar. Podemos ilustrarlo con un ejemplo: el caso de una persona que vivió en una ciudad obrera donde residen principalmente obreros de origen francés y que fue a la escuela con niños de ejecutivos que vivían en el mismo municipio. Esta familia vivió unos diez años en este espacio residencial a su llegada a Francia. 
«Esta vecina que era una gran amiga de mi madre, sirvió a mi madre de vínculo entre la sociedad francesa y su cultura de origen. Ella [la amiga, mujer de un obrero, ambos de origen francés] ayudó también a la integración inmediata de los hijos en la cultura francesa. Tuvo un papel emancipador para la familia, aunque no sea siempre bien visto. (...) La frecuentación de otro medio social me ha dado otra visión, una mirada, una mayor apertura (...) sin mis amigos, habría probablemente optado por una actitud más reservada, una elección más temerosa [referente a la orientación escolar] pero como querían que me quedase con ellos y tenía la capacidad académica, he hecho el bachillerato en ciencias (...). He sido marcado, no sólo influido, por estas relaciones con amigos de origen social diferente, sin que sea más alto» ${ }^{10}$.

Desde los espacios residenciales, han surgido varias prácticas sociales: referidas especialmente a las relaciones de sociabilidad con el vecindario francés, las prácticas socio-educativas que valoran el éxito escolar, la emancipación de las mujeres (que puede traducirse para las madres en cursos de alfabetización, obtención de un permiso de conducir, etc.). A partir de la localización y lo que entraña en función del entorno social, las familias han desarrollado modos particulares de relaciones sociales y familiares. Algunas han privilegiado, por ejemplo, las relaciones con el vecindario francés (lo que se refleja en un mejor dominio del idioma francés), y/o el repliegue sobre la célula familiar (teniendo como consecuencia, por ejemplo, la movilización para el éxito escolar de sus hijos), y/o las relaciones de sociabilidad con las familias del mismo origen (que pueden proporcionar solidaridad y apoyo, etc.).

Las modificaciones de las prácticas familiares han sido particularmente sensibles en las trayectorias sociales de los ejecutivos ${ }^{11}$ : Observamos que éstos, más que los empresarios, han crecido en un entorno residencial heterogéneo (donde domina una mezcla social y/o cultural), dentro del cual las redes relacionales, las actividades practicadas y la atención prestada a los niños (resultados escolares, etc.) han sido determinantes. La expresión «encerrarse para salir adelante», empleada especialmente con referencia al éxito escolar en el mundo obrero, cobra aquí todo su sentido. Los padres han privilegiado las relaciones dentro de la familia y con el vecindario francés (papel de la escuela, prácticas domésticas «europeas», etc.), en detrimento, con frecuencia, de las relaciones con los miembros de la comunidad de origen. De hecho, hay dos actitudes enfrentadas sobre este tema: la que privilegia la proximidad con las familias del mismo origen y la que busca alejarse de ellas. En el primer caso, las familias continúan viviendo según los valores que fundamentan una fuerte distinción entre generaciones y entre los sexos, y según los valores correspondientes a la sociedad de origen. En el caso contrario, los padres están mucho más volcados hacía sus hijos, dando prioridad al diálogo entre cada miembro de la familia -dentro de la pareja, entre padres e hijos. La mirada, los discursos y las prácticas están entonces menos orientados al exterior. Los niños pueden ser objeto de una mayor atención, lo cual se percibe con claridad en los comportamientos escolares. 
«Muchos se han quedado en su rincón, sin moverse de sus pequeños apartamentos [falta de espacio y comodidad, aunque tengan ya niños grandes, pero esto [para esos padres] les ha hecho muy bien puesto que han tenido que adaptarse a un nuevo ambiente y... como estábamos menos en contacto [con la comunidad de origen], hemos podido, iba a decir, avanzar.»

El desarrollo de las sociabilidades en el mundo francés y la comparación que se efectúa inevitablemente con las personas frecuentadas en la escuela, contribuyen en gran medida a la afirmación de nuevas aspiraciones. El papel de la mezcla cultural y/o social es aquí determinante: se expresa, en primer lugar, en el vecindario y en la escuela. Los padres de los ejecutivos se encuentran con mayor frecuencia en este caso tipo. Si siguen viviendo en un barrio de viviendas sociales, el espacio familiar y/o la práctica de actividades fuera del barrio se vuelven predominantes. Han podido también intentar mudarse para salir de un entorno que juzgaban desfavorable a la escolarización y/o emancipación de sus hijos. La creación de nuevos horizontes de lo posible que se sobreponen y prolongan sobre la célula familiar va a determinar ${ }^{12}$ su itinerario posterior, bien en el ámbito residencial, relacional o profesional.

Padre: Con mi mujer, hemos hecho frente común, uno a cada lado [para apoyar a los niños] y sólo pensábamos en ello, la escuela, y cómo he sufrido yo en el trabajo.

Hijo: Es verdad que había un imperativo aquí, ila escuela! (...) Durante las vacaciones escolares con el Ayuntamiento, teníamos que movernos, habia que salir.. era tremendo. Nunca he viajado tanto.
Padre: Trabajo mucho para los niños y no me interesa saber lo que pasa fuera, incluso en el vecindario. Aqui son los niños: ¿qué necesitan? ¿Dónde están? (...) No teníamos muchos contactos, no he intentado... no es desconfianza, no, es que, no es eso, es que no tenemos tiempo.

Hijo: Como decía mi padre, éramos... ellos llos vecinos, la gente de la comunidad] y nosotros, nuestros padres y sus hijos, y teníamos pocas relaciones fuera de la familia.»

La cuestión de la localización muestra así que los itinerarios residenciales, por tratarse tanto de un desplazamiento en el espacio físico como social, tiene importantes repercusiones en el seno de la estructura familiar.

\section{El acceso a la propiedad}

En la encuesta que fue aplicada a 100 personas, más de dos tercios declaran que sus padres ocuparon, en un momento u otro de su itinerario residencial, una vivienda social. En el momento de la encuesta sólo un tercio de los padres residía en este tipo de vivienda; la habían abandonado para conseguir un alojamiento en el sector privado o porque optaron por la propiedad privada. De tal manera que casi la mitad de los padres son ya propietarios de su vivienda en Francia (44\%), y un cuarto optó por un alquiler en el sector privado ${ }^{13}$ Esto demuestra, en ambos casos, la voluntad de dejar la vivienda social y un dominio de los desplazamientos en el espacio urbano. Sin embargo, hay que mencionar que estas familias extranjeras o de origen extranjero no logran conseguir en el sector público un alojamiento en el municipio que quisieron (debido 
a las políticas discriminatorias que apuntan a rechazar a las personas de origen extranjero, sea porque el municipio considera que existe ya un porcentaje de población extranjera importante y/o porque no desea recibir más por temor a alterar su imagen). Pasarse al sector privado y más aún comprar, forma parte de una estrategia para disponer de un mayor margen de maniobra. Este proceso podría no ser, en ciertos casos, resultado de una preferencia sino más bien una manera de evitar una coacción (la de no poder dejar el barrio donde residen para irse a otro de su elección). $\mathrm{Si}$ bien este caso no es raro, es más frecuente que la adquisición responda a una preocupación por construir, por poseer una casa que designe a la vez al edificio y sus habitantes, por extensión, el proyecto de perpetuarse y enraizarse en el país. «La casa es inseparable de la familia como grupo social estable y como proyecto colectivo de perpetuarlo» ${ }^{14}$.

Por un lado, este acto marca indiscutiblemente una inflexión en el proyecto migratorio $y$, por otro, la realización de un proyecto de promoción social, inherente al proyecto migratorio (aunque no se puede deducir con ello que existe una ruptura de los vínculos con el país de origen ${ }^{15}$ ). De la misma manera que la compra de una casa representa el éxito desde el punto de vista del país de origen, varias décadas después de su llegada, marca también el éxito desde el punto de vista del país de acogida: si los padres no han tenido éxito profesional, la casa puede compensar esta desilusión. Retrospectivamente, se trata de reconocer este objetivo y darle forma. El segundo aspecto subyacente es el reconoci- miento de su permanencia: si esta ambición no se manifestó a la llegada, se impone y materializa después con la adquisición de una vivienda.

La diferencia entre mis padres y los de otros es que mi madre se daba cuenta de que hiciera lo que hiciera, que sus hijos estuvieran bien vestidos, tranquilos, limpios, que cumplieran con los deberes de la escuela, no eran aceptados, y llegó a la conclusión «necesito algo para mí». Entonces, compraron una primera casa [como no era lo suficiente cómoda, se mudaron a una vivienda social durante cinco años y luego se construyeron una casa; segunda compral. Pasábamos a un nivel superior y es verdad que, aunque mis padres eran analfabetos, por haber crecido en un ambiente donde habia muchas familias francesas éramos los únicos Magrebíes que vivíamos en casas como los franceses, teníamos un jardín como los franceses, estábamos asimilados a ellos $y$ además con un «cierto encanto particular» (...) decía mi madre, era «estar en Francia», en algún sitio, era... subir en la escala social, vivir en Francia mediante una propiedad (...) mi madre es muy ambiciosa, es parte de ello [del hecho de hacerse propietario], recuerdo cuando éramos pequeñas [con mi hermana], nos sentaba en la mesa y nos hacía trenzas... lo cual era como el símbolo de la "chica de la escuela", se esforzaba por darnos la apariencia de todas las chicas de la escuela (...) tenía tanto miedo a que fuésemos diferentes de los franceses.»

Este movimiento hacia la propiedad comenzó a finales de los años 60 y en los $70^{16}$ y se aceleró mucho durante la década de los 80 y 90. $\mathrm{Si}$ consideramos que la edad media de la población entrevistada era de 35 años (o sea, 20 años en 1980), el acceso a la vivienda se produce cuando los hijos (especialmente los 
entrevistados) han alcanzado la edad adulta. De modo que esta decisión surge cuando ya habían pasado muchos años en Francia, bajo la influencia de los hijos y de las madres. Los datos en este sentido son unánimes: son, ante todo, las madres las que han encaminado la decisión (por muchas razones: marcar su presencia ante sus hijos, la casa como símbolo de éxito, etc.).

La adquisición de una casa tiene lugar normalmente en el segundo anillo (o sea, en los municipios de Décines, Meysieu, Feysin, StPriest...) por razones de precio del terreno o en el centro de la ciudad (Lyon, Villeurbanne...) cuando se trata de la compra de pisos. Las casas son de dos tipos: un pequeño chalet nuevo en una parcela o bien una casa antigua para reformar que la empresa vende a sus empleados (por ejemplo, en el caso de Rhône-Poulenc en Décines). Forman entonces parte de un parque de viviendas que se venden por estar deterioradas.

En el momento del estudio el $35 \%$ de las personas entrevistadas eran propietarias de sus viviendas. Muchas encuestas señalan que sus padres eran propietarios en Argel y/o en Francia para explicar que fuesen ellos mismos propietarios o que piensan, aludiendo a algún modo de transmisión del estatus, disponer de ese capital. Para otros, en cambio, se hace referencia más bien a la voluntad de romper con las prácticas familiares que tenían como único objetivo volver al país de origen. Adquiriendo una propiedad inmobiliaria esperan afianzar su presencia en Francia, contrariamente a lo que hicieron sus padres. Ser propietarios de una vivienda per- mite no depender de arrendamiento, «estar en su casa, pero también estar en su casa en Francia» ${ }^{17}$ Además, constatamos que los espacios residenciales habitados por la segunda generación son sensiblemente diferentes de los que tenían los padres. Las viviendas son de mejor calidad, los barrios con mejor reputación y se aprecia una mayor inversión en la vivienda porque existen menos limitaciones financieras (ingresos más altos que los de los padres) y están menos propensos a proyectos de regreso. Desean también adaptarse a los valores y modos de ser vigentes en la sociedad francesa, a categorías socio-profesionales equivalentes (adquisición de muebles, electrodomésticos, Hi-Fi, etc.; lo mismo que cuando los padres logran adquirir una propiedad). De ese modo, el sentimiento de pertenencia ligado a la antigüedad y/o adquisición, se manifiesta por un mayor consumo de bienes y por la reforma de los espacios habitados. Hay que señalar también que la segunda generación depende menos que los padres de los organismos públicos de viviendas. Finalmente, ser propietario permite a veces compensar la falta de movilidad profesional o bien, al contrario, reforzarla. En algunos casos, la propiedad representa también, para los empresarios, un capital que puede ser movilizado para la creación de una empresa: se vuelve entonces posible lanzarse en la aventura empresarial puesto que se dispone de una propiedad que permite obtener un préstamo bancario más fácilmente. Según el análisis de I. Bertaux-Wiame y A. Gotman ${ }^{18}$, podemos considerar esta adquisición como un «trampolín». 
A pesar de las diferencias constatadas entre las dos generaciones a nivel de prácticas residenciales los hijos privilegian a menudo la cercanía con la vivienda de los padres. Permite intercambiar favores, facilitando así muchas cosas para ambas partes en la vida cotidiana $^{19}$. Este será el tema del tercer capítulo.

Respecto a cómo se trasmite el estatus de propietario, cabe señalar que 83 entrevistados afirmaron que sus abuelos paternos eran propietarios de su vivienda en Argel (y 71 de sus abuelos maternos). Los hermanos y hermanas de los entrevistados son, por otra parte, propietarios en un $20 \%$ de los casos. A. Gotman ${ }^{20}$ escribe: «El estatus individual de propietario puede ser caduco puesto que el hecho de pertenecer a una familia donde la propiedad empieza a difundirse es ya un indicador de pertenencia de clase. Es la familia, y no el individuo, el verdadero miembro de la clase.» Mediante las cifras, nos damos cuenta que el estatus de propietario se transmite ${ }^{21}$ de una generación a otra y da testimonio de las aspiraciones y las estrategias que se ponen en marcha para adquirirla y conservarla ${ }^{22}$. Finalmente, la cuestión del acceso remite a la dimensión intergeneracional en la medida que se observan numerosas movilizaciones en el seno de las familias para permitir o facilitar la adquisición de la vivienda.

\section{El intercambio de ayudas entre las dos generaciones}

Pasamos a describir ahora tres tipos de ayudas: las que dependen de los recursos financieros y morales cuando se adquiere una vivienda, la ayuda mutua cotidiana, y el desarrollo de las actividades profesionales.

\section{Las movilizaciones financieras y morales}

El acceso a la propiedad de los padres no puede ser plenamente entendida sin cuestionarse la participación financiera y moral de los hijos ${ }^{23}$. Es una forma de ayuda entre generaciones que influye decisivamente sobre la movilidad residencial. Tanto la decisión de adquirir una vivienda como los medios para lograrlo y su significación dentro del proyecto migratorio, dependen de decisiones y negociaciones dentro de las familias cuyos miembros pueden movilizarse de distintas maneras para llegar a superar esta etapa. Hay que señalar que, contrariamente a lo que sucede en las familias francesas, no son los padres sino los hijos quienes cumplen un papel decisivo en este proceso, contribuyendo financiera $y$ moralmente ${ }^{24}$ en la adquisición de una vivienda para los padres.

En el ámbito financiero hemos encontrado diversas configuraciones: o bien, uno o varios hijos, (por ejemplo, con un préstamo compartido) obsequian la vivienda a los padres, o bien, los hijos (o una parte de ellos, muchas veces los mayores o los que tienen un empleo) se encargan de los gastos esenciales a la vivienda familiar, incluso los que la han abandonado para comprar su propia vivienda. En el ámbito moral se movilizan para proporcionar diferentes tipos de ayudas (gestiones administrativas y bancarias, trabajos y acondicionamientos, etc.) y, sobre todo, para animar a los padres a adquirir su propia vivienda. Representan uno de los elementos motores de 
esta decisión por el hecho que, ellos, permanecerán en Francia. Contribuyen de esa manera a influir sobre el proyecto migratorio y, simultáneamente, a marcar una presencia que se afianza y quiere ser diferente.

\section{La ayuda mutua}

La movilización de los hijos durante el trámite de adquisición es muy grande y aumenta a medida que la proximidad geográfica y los vínculos afectivos entre los miembros de la familia son estrechos. Lo mismo sucede con respecto a las otras formas de ayuda mutua. Esta constatación viene a subrayar, por una parte, la fuerte proporción de miembros de la familia que residen cerca unos de los otros (o sea, en el mismo municipio, el mismo Distrito o entre un Distrito de Lyon y un municipio una localización próxima al antiguo barrio de residencia. Estos dos aspectos están, además, estrechamente vinculados entre sí. Es frecuente constatar, por ejemplo, que durante la «des-habitación» un entrevistado alquilaba un piso en el Distrito VII de Lyon mientras que había crecido con sus padres en Vénissieux, municipio limítrofe donde siguen viviendo después de haber estado en St-Fons a su llegada. El desplazamiento residencial tiende, por lo tanto, a efectuarse según la linealidad geográfica privilegiando la proximidad espacial con los miembros de la familia y con el barrio en el cual se ha vivido durante muchos años ${ }^{25}$. A la vez, la proximidad espacial favorece los vínculos familiares, lo que se manifiesta en distintos tipos de prácticas cotidianas relacionadas con el entorno inmediato.

La custodia de los nietos es la ayuda citada con mayor frecuencia. Pero muchos otros servicios se intercambian también entre padres e hijos (recados, gestiones administrativas, desplazamientos en coche, etc.) Estos intercambios de servicio forman parte de la «economía invisible y subterránea ${ }^{26}$. La reciprocidad de los intercambios tiene lugar habitualmente en materias diferentes y no al mismo tiempo. Por ejemplo, una madre cuida a sus nietos durante el día, mientras uno de sus hijos la lleva en coche más tarde para hacer la compra, la ayuda en sus gestiones administrativas, le da consejos, etc.

La situación de los padres en Francia refuerza la necesidad de estos intercambios y, por consiguiente, de los vínculos: los hijos se sienten responsables de sus padres puesto que muchos de ellos son analfabetos, no hablan francés, no conducen un coche y/o están agotados por una larga vida laboral. Por consiguiente, la movilidad profesional y social no va acompañada de un distanciamiento que se expresa en el plano afectivo y geográfico. El éxito socio-profesional de los hijos y, por consiguiente, la distancia que se crea en ese aspecto, no implica una ruptura o al menos una distancia en cuanto a intercambios familiares. Al contrario, éstos tienen lugar dentro de un territorio urbano relativamente limitado: la proximidad geográfica descubre entonces la intensidad de los vínculos familiares $y / o$ afectivos. Sea cual sea la actividad profesional de los hijos y la distancia entre ellos y sus padres (normalmente obreros), las marcadas distinciones en el espacio social no suelen alterar los vínculos familiares, contrariamente a lo que se puede observar en muchas familias 
donde el ascenso social de los hijos conduce a una ruptura familiar ${ }^{27}$. Los modos de vida son seguramente distintos, sus aspiraciones y relaciones también, pero el reconocimiento hacía los padres es tan fuerte que, en la mayoría de los casos, el sentimiento de deber ayudarles, de estar presente cerca de ellos, permanece muy vivo. Sin embargo, pueden aparecer tensiones, incluso conflictos, negociaciones, aunque globalmente las relaciones familiares parezcan muy unidas.

\section{Desarrollo de las actividades empresariales}

Otro tipo de ayuda mutua se observó con los empresarios que pudieron desarrollar sus actividades gracias al apoyo familiar. En más de la mitad de los casos miembros de la familia, principalmente hermanos y hermanas, les han prestado ayudas más o menos formales $y$ regulares. Adoptan formas distintas y variables según las necesidades de las empresas: trabajos de acondicionamiento, préstamo en dinero, abastecimiento, participación como asalariados, limpieza, contabilidad, echar una mano etc.

La proximidad geográfica entre los miembros de la familia y la escasa distancia entre el lugar de residencia y el lugar de trabajo es todavía más importante en el caso de los empresarios. Instalar su actividad profesional en el barrio donde han crecido y/o cerca de su familia asegura una serie de recursos que pueden movilizar para su actividad económica. Esto es patente en los comerciantes que se instalan en el barrio de su infancia, en el que, a veces, siguen viviendo y donde se abren un restaurante, una panadería, una carnicería, un estanco, etc. Estos barrios son generalmente de viviendas sociales, o sea, de espacios residenciales que pueden ser beneficiarios de programas públicos que, a su vez, van a favorecer la creación de actividades comerciales: estos empresarios aprovechan en tal caso estas ayudas como las destinadas a la reapertura empresas cerradas por motivos económicos ${ }^{28}$.

La integración de la actividad comercial en la comunidad familiar y cultural parece entonces un hecho indisociable: los clientes, las redes comerciales, la mano de obra (eventual y regular) forman parte en su mayoría del entorno inmediato; esto no significa, sin embargo, que sus actividades estén destinadas exclusivamente a la comunidad de origen -lo cual es más bien raro. Este estrecho vínculo es significativo ante lo que ocurre en el espacio residencial: o bien la actividad se realiza en el mismo barrio donde residen, a menudo con miembros de su familia y de la comunidad de origen, o bien el alojamiento sirve de lugar de producción. Algunos comerciantes cuyos padres han llegado a adquirir una propiedad, utilizan el garaje para fabricar productos que venden luego en los mercados (como cojines). Algunos hermanos y hermanas, a veces el padre, se incorporan a esta actividad: trabajan muchas horas por semana en la confección o en los mercados. La ayuda prestada por miembros de la familia se revela por lo tanto determinante: señala el estrecho vínculo que existe entre el lugar de residencia y la actividad profesional, y esta movilización familiar es más importante mientras más cerca se encuentren. 
Las relaciones intergeneracionales se perfilan claramente al hilo del itinerario residencial: son representativas de unas decisiones que se toman dentro de la familia. Así que, para concluir, aunque no se puede negar que gran parte de estas familias ha sufrido por sus condiciones de alojamiento, parece ser que la cuestión de los itinerarios residenciales no puede entenderse considerando sólo los temas de segregación, del cautiverio residencial, etc. Muchos otros aspectos, por ser internos a las familias, aparecen solamente implícitos. Esta constatación implica el reconocimiento de la heterogeneidad de las familias inmigradas argelinas, en consecuencia de la heterogeneidad de itinerarios sociales, donde el itinerario residencial en Francia es sólo una de sus facetas. Además, la diversidad de itinerarios obliga a tener en cuenta la pluralidad de las experiencias a partir de las cuales se elabora el proyecto residencial y todo otro proyecto, aspiración, práctica, universo de referencias, etc., particular de cada familia y de sus actividades entre Argel y su establecimiento en Francia. La pluralidad de los itinerarios residenciales indica asimismo la heterogeneidad de los medios financieros entre las familias. En realidad, dependiendo de si se dispone o no del apoyo financiero de los hijos, de si el padre ha tenido alguna promoción y/o si la madre trabaja, del orden de prioridades (inversión inmobiliaria o financiamiento de los estudios superiores de los hijos), las familias no dispondrán de las mismas condiciones para enfrentarse a la movilidad residencial, especialmente cuando se trata de adquirir una propiedad privada.
Muchas preguntas quedan en el aire a las que futuros trabajos etnológicos podrían intentar responder, por ejemplo, acerca de la organización de los espacios residenciales (interior y exterior), de las relaciones de vecindario, la transmisión de un bien inmobiliario a los hijos, la gestión de un doble patrimonio de un lado a otro del Mediterráneo, las repercusiones de las infraestructuras en una urbanización al momento de la compra, los obstáculos financieros, etc. ${ }^{29}$. A pesar de que hay todavía muchos campos poco explorados, podemos insistir de entrada en la similitud con los itinerarios residenciales de las familias de origen francés. Tanto en lo referido a la «transmisión» del estatus de propietario, como a la búsqueda de proximidad geográfica entre miembros de la familia, o al proyecto de adquisición de una propiedad privada, parece haber similitudes con lo analizado en numerosas investigaciones sobre el alojamiento y el itinerario residencial de familias de origen francés.

No obstante, merecen señalarse tres diferencias, de las cuales una sirve para insistir en las dificultades particulares que encuentran las familias inmigradas ante las actitudes discriminatorias. En primer lugar, una de las diferencias es que la primera generación de inmigrados, los padres, no tiene acceso a la propiedad en la misma fase de su ciclo de vida que las familias de origen francés. La permanencia del proyecto migratorio durante muchos años tiene como consecuencia «retrasar» esta decisión. En segundo lugar, son los hijos los que se movilizan para financiar a los padres durante esta etapa residencial. Aunque 
estudios recientes sobre los tipos de ayuda mutua y de solidaridades familiares señalan la importancia de estas ayudas intergeneracionales destinadas a la compra de una vivienda, en la población de origen francés esta ayuda va de padres a hijos. Este proceso «inverso» puede explicarse, por un lado, por el estatus socio-profesional del padre (en este caso hay situaciones análogas que pueden muy probablemente detectarse en las familias obreras de origen francés). Por otra parte, esta movilización parece todavía más importante cuando los hijos sienten la obligación de apoyar a los padres por las condiciones laborales sufridas en Francia durante largos años, el racismo, la esperanza de volver al país de origen, el analfabetismo, etc. Además, el apoyo financiero es muchas veces indispensable para que los padres pueden pedir un préstamo. Los bancos conceden difícilmente préstamos por cantidades relativamente elevadas y a largo plazo a estos padres inmigrados y obreros, cerca de la jubilación. El aval financiero de los hijos permite frenar las negativas. Los hijos que se sienten a menudo en deuda con sus padres tienen así la posibilidad de expresar su reconocimiento. Muchos de los que tienen éxito profesional estiman que sus padres han contribuido mucho a ello y acuden a su vez a ayudarles, así como al establecimiento de la familia de Francia. En tercer lugar, estas familias tienen que enfrentarse a una desconfianza, por no decir un rechazo, por parte de las instituciones bancarias, de los representantes políticos, del personal administrativo de los municipios donde se instalan o donde quieren comprar una vivienda $a^{30}$. Como individuos o representantes de una institución, estas personas tie- nen la sensación que la llegada de estas familias trae o traerá problemas similares a los que se han producido en los barrios de viviendas sociales. Implícitamente, se sobreentiende que contribuyen al deterioro físico y simbólico del lugar.

Mientras que durante muchos años se ha defendido la idea de que la mejor solución para resolver los problemas del extrarradio era la dispersión espacio-residencial de las familias, ahora que «se dispersan» en el espacio urbano - como consecuencia de los programas de asignación de viviendas públicas, numerosos discursos vuelven a criticar su presencia, lo cual deja entrever nuevas crisis locales (delincuencia, conflictos de vecindario, devaluación de las viviendas situadas en la proximidad de estas familias, etc.). Esta actitud discriminatoria acentúa la dificultad de estas familias para encontrar una ubicación en la ciudad: que vivan en los barrios periféricos, que sean minoritarias en un barrio residencial o que se encuentren con otras familias de origen extranjero en una parcela, los mismos discursos reaparecen, dando prueba que los juicios xenófobos ponen en cuestión la capacidad de integración de estas familias. 31

Sean cual sean las motivaciones de los desplazamientos residenciales (imposibilidad de conseguir un alquiler en la zona elegida, preferencia en la adquisición de una propiedad, búsqueda de la proximidad con los miembros de la familia, etc.) y el tipo de localización (casa, piso, sector deteriorado o valorado, pequeña o gran ciudad, campo, etc.) se observa que gran parte de estas familias no son dependientes del espacio residencial. En 
cambio, su presencia en los distintos territorios es objeto de debates y discriminaciones. Así que independientemente del estatus residencial o de si estas familias están reunidas o separadas en el espacio urbano las situaciones de segregación detectadas son numerosas. Esta exclusión espacial es el correlato de la exclusión social que amenaza a estas poblaciones. En otros términos, lo que se expresa aquí no es tanto el rechazo de los inmigrados como el temor a que puedan penetrar en ciertos espacios; espacios resi- denciales, pero también profesionales, cívicos, políticos, etc. La cuestión del sitio que pueden (y deben) ocupar en la sociedad francesa sigue en el orden del día: implica reconocer que existe una relación social dentro de la cual se negocian posiciones sociales. V. de Rudder señaló esta cuestión en la introducción a un coloquio sobre las relaciones inter-étnicas dentro de la ciudad ${ }^{32}$ : las nociones de segregación y exclusión tienen en común evadir las relaciones sociales que están en su origen.

\section{NOTAS}

' El trabajo de investigación fue realizado a partir de un dispositivo que combinaba una parte de la cuarentena de entrevistas $y$, por otra parte, un cuestionario aplicado a 100 personas. La población entrevistada, que se compone de dos sub-poblaciones (los ejecutivos y empresarios cuyos padres han emigrado de Argel), ha crecido y vive hoy principalmente en la región de Lyon. Cf. Des cheminements sociaux à la construction de trajectoires professionnelles. Histoires familiales, relations sociales et mobilités. Des cadres et des entrepreneurs d'origine algérienne. Tesis doctoral en sociología y ciencias sociales leida en la Universidad de Lyon II bajo la dirección de Yves Grafmeyer, 907 páginas, 3 tomos, 1997. Una obra va a salir en la editorial Presses Universitaires du Mirail en septiembre de 2001 bajo el título La mobilité social dans l' inmigration. Itinéraires de réussite des enfants d'origine algérienne.

${ }^{2}$ Cf. Itinéraires ouvriers. Espaces et groupes sociaux à Turin au début du vingtième siècle, EHESS, París, 1987. ${ }^{3}$ Ya los primeros trabajos de la Escuela de Chicago colocaban en el centro de sus preocupaciones este cuestionamiento sobre las distribuciones socio-espaciales.

${ }^{+}$Cf. el artículo P.Videlier sobre la región de Lyon, «Les voies de la migration. Italiens et Algériens dans l'espace lyonnais», Le monde alpin et rhodanien, núm. 3/4, 1989. ${ }^{5}$ Cf. A. Begag, Place du pont ou la Médina de Lyon, Autrement, coll. «Monde», París, 1997.

${ }^{6}$ Habitat à Loyers Modérés (Vivienda de protección ofi(ial).

${ }^{7}$ En el censo de $1990,41,2 \%$ de las familias cuya persona de referencia había immigrado desde Argel eran inquilinos de una vivienda de protección oficial (HLM). Entre las poblaciones immigradas, las familias originarias de Argel representan la mayoría de los inquilinos de esas viviendas. Cf. Les immigrés en France, Contours et caractères, INSEE, París, 1997.

${ }^{8}$ El trabajo realizado en el barrio de Bron-Parilly, descrito como muy deteriorado y denigrado, demuestra que un gran número de familias desea vivir en el barrio, eventualmente cambiar de vivienda dentro del barrio, incluso en el mismo edificio. Muchos también desean dejarlo, pero algunos precisan que les gustaría encontrar una vivienda cerca del barrio donde han vivido muchos años y donde encuentran referencias, redes de sociabilidad, etc. Algunas familias entrevistadas han logrado, por otra parte, comprar una casa o alquilar un piso permaneciendo en el mismo sector de Bron. Una conversación escuchada recientemente en un transporte público entre dos cuadros de la OPAC encargada del barrio de Bron-Parilly daba testimonio del asombro frente a estas familias que no desean mudarse o que desean mudarse en las proximidades del barrio (en el barrio de los Essarts, por ejemplo), incluso en el mismo edificio.

${ }^{9}$ Que se resume así: inmigración por motivos económicos, vivienda insalubre (ciudad de tránsito, amueblado, etc.) a la llegada y esto, durante años, después acceso a la vivienda social y a veces se mantiene este tipo de vivienda después de haber pasado décadas en Francia.

${ }^{10}$ Hay que precisar que la madre de este entrevistado hizo la escuela primaria en Argel, hablaba francés antes de inmigrar, la abuela materna tenía una actividad profesional, y vivieron en una gran ciudad argelina después del fallecimiento del abuelo materno. Estas diferentes características han tenido, por consiguiente, incidencias sobre el proceso de socialización familiar. En este ejemplo, el entrevistado muestra el vínculo entre las características de su madre y el encuentro con una vecina francesa que introducir en la familia a la sociedad francesa. 
"Una de las dos sub-poblaciones investigadas̀ en el marco de la tesis. Cf. E. Santelli, «Entrepreneurs et cadres d'origine algérienne à Lyon. Deux stratégies d'intégration», Les Annales de la recherche urbaine, núm. $76,1997$.

${ }_{12}$ Acepción definida en el artículo de D. Bertaux y $\mathbf{I}$. Bertaux-Wiame, «Le patrimoine et sa lignée: transmissions et mobilité sur cinq générations», Life stories/Récits de vie, núm. 4, 1988, p. 23.

${ }^{13}$ En el censo de 1990 , el $19,4 \%$ de las familias cuya persona de referencia ha inmigrado desde Argel eran propietarias de su vivienda. Entre las poblaciones inmigradas, las familias de origen argelino representan el grupo minoritario de propietarias de su vivienda. Y cerca del $30 \%$ eran inquilinos de una vivienda que no cra de protección oficial (a título de recordatorio: $41,2 \%$ eran inquilinos de una vivienda de protección oficial y $10 \%$ ocupaba otro tipo de vivienda). Cf. Les immigrés en France, Contours et caracteres, INSEE, París, 1997.

${ }^{14} \mathrm{Cf}$. P. Bourdieu, «Un placement de père de famille», Actes de la recherche en sciences sociales, núm. 8I/82, 1990 .

15 Las estancias durante las vacaciones o parte del año son, de hecho, todavía muy frecuentes para la mayoría de los padres. Además, la casa que poseen en el país de origen ha sido adquirida muchas veces antes del alquiler en Francia, y las diferentes formas de inversión son signos de la persistencia del vínculo con el país de origen. Este proceso es similar al que se observa en otras poblaciones inmigradas, como los portugueses o turcos. A cambio, podemos preguntarnos sobre el sentido de la gestión relativamente tardía de la población de origen argelino para ser propietaria con relación a estas poblaciones.

16 14 parejas de padres han conseguir obtener una propiedad en 1980.

17 Más que una mera inversión -lo cual es la justificación más extendida- la vivienda aparece también como una inversión social.

${ }^{18} \mathrm{Cf}$. «L'accession à la propriété dans le parc social: quelle demande?», Les Annales de la recherche urbaine, núm. 65, 1994.

${ }^{19}$ De hecho, un gran número de trabajos ha analizado cómo estas ayudas intervenían dentro de las familias. Cf. A. Pitrou, Les solidarités familiales, Privat, Toulouse, 1992; F. Bloch y M. Buisson, «La circulation du don entre génération ou comment reçoit-on?», Communication, núm. 59, 1994; C. Attias-Donfut (bajo la dirección de), Solidarités entre générations. Vieillesse, familles, Etat. Nathan, coll. Essais et recherches", París, 1995; J. C. Kaufmann (bajo la dirección de), Faire ou faire-faire? Familles et services, Presses universitaires de Rennes, coll. «Le sens social», Rennes, 1996.

${ }^{20}$ Cf. Héritier, PUF, París, 1988, p.48.
21 De la misma manera que lo observaron los siguientes sociólogos en investigaciones dedicadas a la población francesa. Cf. C. Bonvalet, A. Gotman, I. Bertaux-Wiame, P. Cuturell, Y. Grafmeyer, D. Maison, P. A. Rosental, Le logement, una affaire de famille. L'approche intergénérationnelle des statuts résidentiels, L'Harmattan, París, 1993.

${ }^{22}$ El estudio realizado por C. Bonvalet, A. Gotman y Y. Grafmeyer (eds.), I. Bertaux-Wiame, D. Maison, L. Ortalda, proporciona numerosas ilustraciones de ello. «Proches et parents: l'aménagement des territories», INED dossiers et recherches, núm. 64, diciembre 1997.

${ }^{23}$ Cf. E. Santelli, «La mobilisation des familles algériennes pour l'accession à la propriété. Le rôle décisif des fils», Les Annales de la recherché urbaine, núm. 59/60, 1993.

${ }^{24}$ Términos empleados con relación al trabajo de P.Cuturello y F. Godard, Familles mobilisées, LATAPSESGERM, Nice, 1980.

25 Solo 4 entrevistados sobre 100 han contestado que ninguno de sus hermanos y hermanas vive en el mismo municipio que la de los padres mientras que 38 contestaron que sí viven en el mismo municipio que los padres. ${ }^{26}$ Tal como la ha llamado A.Pitrou, Les solidarités familiales, op. cit.

${ }^{27}$ Cf. V. de Gauléjac, La névrose de classe, Homme et groupes éditeurs, París, 1987. Las novelas de A. Ernaux ilustran también de manera muy significativa esta constatación, especialmente en La place, Gallimard, París, 1983.

${ }^{28}$ Cf. E. Santelli, «Entrepreneurs et cadres...», op. cit.

${ }^{29}$ Se ha iniciado un trabajo durante el año pasado con $\mathrm{R}$. Bekkar con este propósito. Se trata de una continuación del informe siguiente: Habité et urbanité des immigrés maghrébins en France, R. Bekkar, N. Boumaza, D. Pinson, Plan Construction et Architecture, París, juin, 1995. ${ }^{30}$ Sobre este tema, hay que señalar que cuando contactamos con estas personas o instituciones para obtener informaciones, por ejemplo sobre los tipos de contrato de préstamos, se sobreentendía que este trabajo se dirigía a una población que enfrentaba necesariamente dificultades y que conseguía una vivienda mediante ayudas sociales, o sea, fuertemente ayudadas debido a estas dificultades.

31 Varios discursos apuntan a lo siguiente: «He mirado los nombres en los buzones antes de comprar esta vivienda, para saber si no había negros o árabes en el edificio porque después se alquila con más dificultad. «iEsta persona (...) vive en una parcela?» «Pero ahí hay muchas familias argelinas».

${ }^{32}$ Conferencia del 26 de marzo de 1998 en el marco del coloquio que tuvo lugar en Grenoble (Francia) los días 26 y 27 de marzo de 1998 sobre el tema «L'habitat et la ville au regard des relations interethniques». 


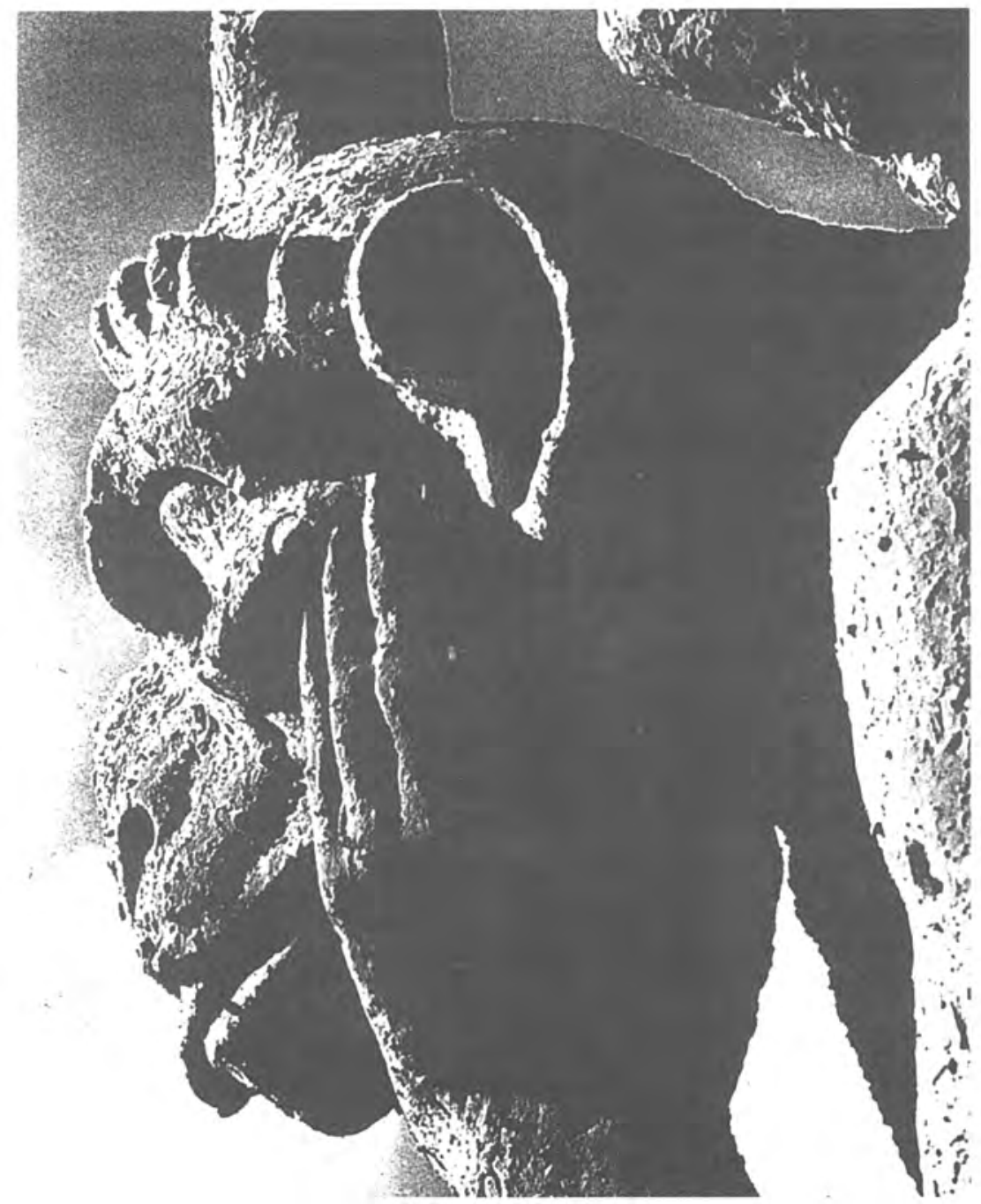

Górgola de la catedral de Notre Dame, París (Foto F. A. 1955). 